\title{
De-constructing the sustainability challenge for engineering education: an industrial ecology approach
}

\section{Michele Rosano and Wahidul K. Biswas*}

Sustainable Engineering Group, Curtin University, GPO Box U1987, Perth, WA 6845, Australia

Fax: +61-08-92664811

Email: m.rosano@curtin.edu.au

Email: w.biswas@curtin.edu.au

${ }^{*}$ Corresponding author

\begin{abstract}
Engineering for sustainable development (ESD) involves engineering decision making that provides for todays production and consumption without endangering the natural resource base on which all of life ultimately depends. Curtin University's Faculty of Engineering in Perth, Western Australia, has long held the belief that engineering education holds one of the main keys to improving sustainable development outcomes across the modern world and to this end has invested in the development of outreach programmes, undergraduate and post-graduate education and the promotion of education leadership in engineering education for sustainable development. These programmes have been both facilitated and developed by the Sustainable Engineering Group in the School of Civil and Mechanical Engineering at Curtin University. De-constructing the sustainable engineering education challenge has involved programmes that start from the first interface with potential young engineers in secondary high schools and continues through to post-graduate education for practicing engineers.
\end{abstract}

Keywords: engineering education; sustainability; industrial ecology.

Reference to this paper should be made as follows: Rosano, M. and Biswas, W.K. (2015) 'De-constructing the sustainability challenge for engineering education: an industrial ecology approach', Progress in Industrial Ecology - An International Journal, Vol. 9, No. 1, pp.82-95.

Biographical notes: Michele Rosano is the Director of Sustainable Engineering Group, Curtin University. Her research interests include life cycle assessment, sustainability matrix and sustainability education. She has worked internationally in the mining industry in a number of senior executive positions, and as a Lecturer and Researcher in Australia. She is currently assisting with the establishment of Australia's first Industrial Ecology Networking organisation.

Wahidul K. Biswas is a Senior Lecturer and Program Coordinator at the Sustainable Engineering Group, Curtin University. He teaches a core engineering unit on Engineering for Sustainable Development to all engineering students at Curtin University. He has carried out extensive life cycle assessment research on environmental emissions from the Australian agricultural, alternative fuels, building and construction, manufacturing, mining, gas and water sectors. 
This paper is a revised and expanded version of a paper entitled 'De-constructing the sustainability challenge for engineering education. An industrial ecology approach' presented at the Engineering Education for Sustainable Development Conference, Cambridge University, UK, 23-25 September, 2013.

\section{Introduction}

Increasing pressures on our resource systems together with increased environmental risks present a new paradigm for engineering education to address. The McKinsey Global Institute in 2011 produced a research report "Resource Revolution: Meeting the world's energy, materials, food, and water needs" which addressed the questions of whether an era of sustained high resource prices and increased economic, social and environmental risk is likely to emerge post recent decades of low resource prices fuelled economic growth.

The report suggests that faced with population increases and the 3 billion additional middle-class consumers expected to be in the global economy by 2030 , the resource productivity required to meet this global resource demand is unlikely to be sufficient to prevent further global warming above the two degrees Celsius that may already be inevitable, or to alleviate the resource poverty that affects so many citizens. They further surmise that delivering the required productivity improvements and supply growth needed is a very large and complex agenda. They suggest a number of actions need to be taken in addressing this challenge including a number in the public policy realm including taking measures to raise awareness about resource-related risks and opportunities, creating appropriate safety nets to mitigate the impact of these risks on the poorest members of society, educating consumers and businesses to adapt their behaviour to the realities of todays resource constrained world, and increasing access to modern energy, so improving the economic capacity of the most vulnerable communities. McKinsey also note that ongoing environmental pressures may constrain production including increased soil erosion, the excessive extraction of groundwater reserves, ocean acidification, deforestation, declining fish stocks and the unpredictable risk-multiplying effects of climate change (McKinsey Global Institute, 2011).

Sustainable engineering practice will be required to provide multi-faceted solutions to these complex problems including the design and management of sustainable technology, assessment of engineering environmental and social impacts, carrying capacity limitations, and management of resources from cradle to cradle (Boyle, 2004).

Engineering decisions are increasingly required to respond to both economic and social pressures whilst taking ecological principles into account. University engineering degrees also need to produce engineering graduates who are able to apply sustainability principles throughout their professional career and can provide ongoing learning programmes that meet the challenges of a changing world.

However, Fenner et al. (2005) report that recent studies of the engagement with the concept of sustainability of both UK construction contractors (Adetunji et al., 2003) and consulting companies (Wordsworth, 2003) showed that at the time, substantial progress had only been made regarding he environmental aspects of sustainable development and that both studies indicated that in many cases there remained a lack of understanding, 
and vagueness about sustainability concepts and their implementation into current engineering practice.

Curtin University approaches the engineering challenges for sustainable development through a variety of programmes that attempt to provide a grounding in sustainable development theory and practice starting with potential engineering students via interactive programmes at secondary schools, engineering for sustainable development (ESD) embedded in current under-graduate programme offerings right through to programmes for post-graduate engineers and managers interested in increasing their sustainability management skill base. This paper highlights four specific areas of ESD education within the School of Engineering at Curtin University:

- a high school outreach (HSO) programme together with Engineers Without Boarders Australia (EWBA) that provides High School students with the opportunity to understand the engineering professions challenges and solutions for sustainable development

- an optional project 'Future Engineers' run in conjunction with the EWBA outreach programme that requires undergraduate engineering students to meaningfully engage with the broader community whilst educating secondary school students in the application of engineering science to solve real world problems

- a mandatory unit in 'ESD' for all under-graduate engineering students

- MSc in sustainability for returning graduates in industrial ecology.

\section{Education for engineering for sustainable development}

The following discussion outlines the above programmes and highlights the ESD education and skills development that is focussed on within the School of Engineering at Curtin University utilising industrial ecology pedagogy.

\subsection{High school outreach (HSO) programme}

The benefits of teaching secondary (high) school students engineering principles and encouraging them to investigate engineering as a profession is well established (Loden and Biswas, 2011; Moskal, 2007).

EWBA designed the HSO workshops to reach the next generation of engineering students and to provide them with an early introduction to engineering initiatives with young under-graduate engineers presenting sustainable development focused engineering applications to them in their high school class environment. EWBA is a not-for-profit member based non-government organisation that works in partnership with developing communities in south Asia, south-east Asia and remote Australia to develop humanitarian engineering programmes to address a lack of access to basic human needs such as clean water, sanitation and hygiene, energy, basic infrastructure and waste systems. The EWBA focuses on educating and training Australian engineering students about the wider community issues facing the engineering profession including sustainable development, appropriate technology and the power of humanitarian engineering (EWBA, 2011). 
This HSO programme was designed by the Curriculum and Research team of the EWBA to achieve two main objectives. Firstly to introduce the engineering profession and relevant sustainable engineering concepts and practices to high school students (Year 10 and 11) and secondly to involve undergraduate engineers in a community outreach programme promoting the profession and extending engineering know how and knowledge to potential future students (Loden and Biswas, 2011). The university student outreach experience is discussed separately in the next section.

The HSO workshops involve the class being briefed by the ESD university students in the first $20 \mathrm{~min}$ of the workshop on the background and sustainability relevance of the topic before being split into 4-5 groups to carrying out the technology development activity. During this activity the ESD University Lecturer would assess the individual groups progress ensuring the topic was being understood and that relevant facets of the sustainable development technology challenge was understood and was translated into the technology development activity.

A survey of the secondary school students and teachers feedback on the outreach programmes run in 2010 was conducted by Loden and Biswas (2010) and they found that the HSO workshops left the students with a good understanding and impression of what it means to be an engineer. The survey also demonstrated some opportunities to improve the quality of the HSO workshops by providing more contextual information on the engineering challenge being presented and a request for more details on the professional practice skills involved. These recommendations were then included in future workshops.

Figure 1 Student response when asked how they benefited from participation in the Future Engineers programme (see online version for colours)

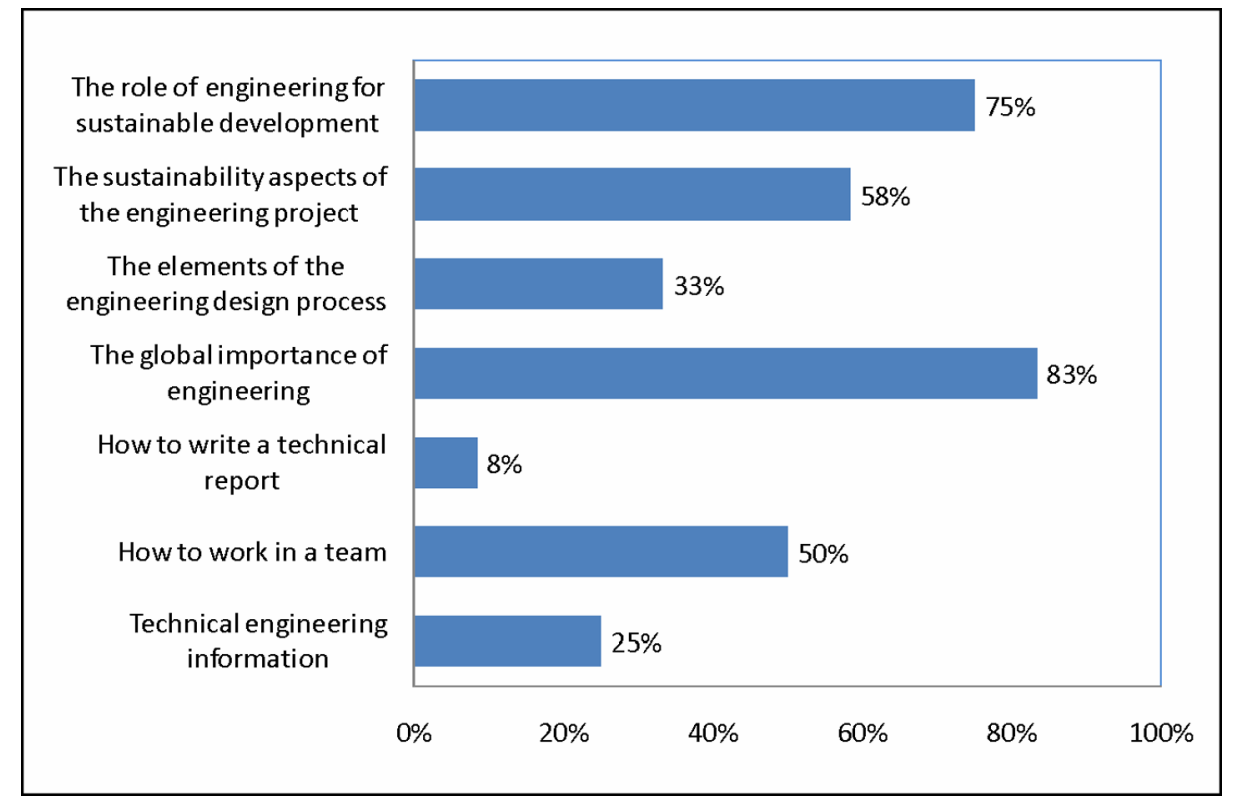

Source: Loden and Biswas (2010)

Figure 1 outlines the student response to the question of how they benefited from participation in the programme in 2010. 
Loden and Biswas noted that the student participants found that they achieved a better understanding of a number of areas in ESD. Specifically $83 \%$ developed a better understanding of the global importance of engineering to society and $75 \%$ an understanding of the role of engineering in sustainable development whilst $58 \%$ developed a deeper appreciation for sustainability aspects in an engineering project.

Overall the HSO has provided an important opportunity for the university to engage directly with the market for engineering students and to introduce them to many of the important sustainable development challenges that face the profession and may well encourage them to consider engineering studies.

\subsection{Future Engineers project}

The Future Engineers Project is the flip side of the OHS programme noted above and started at Curtin in 2010. Students can chose to participate in this outreach project as an optional project in the ESD unit. ESD is a mandatory unit in their degree and is discussed in further detail in the next section. The Future Engineers programme covers $15 \%$ of the ESD units total assessment and replaces a written assignment on triple bottom line analysis which is completed by those students not wishing to participate in Future Engineers project.

The project involves students making presentations at local participating high schools in Perth, Western Australia on one of three sustainable development topics- water supply and treatment, energy and climate change and appropriate construction. The presentation of this subject matter by students to high school students requires the students to investigate the subject matter, develop a suitable mode of presentation delivery to effectively address the high school audience and be able to fully understand the engineering and scientific processes involved in the context of sustainable development.

Each topic group consisting of four students needs to complete two, one hour long workshops, in consecutive weeks at the same high school. The first workshop is conducted on affordable water supply for the developing community and the second workshop on climate change in the following week.

Each topic area involves three lessons with online support available for students in the coordination and delivery of the content (www.ewb.org.ay/hsomodules) (Loden, 2010).

Participating students undertook two training workshops in two consecutive weeks prior to the school workshops on modern water and climate change issues. Before completing these workshops, students presented their workshops to the lecturers, EWB volunteers and tutors to ensure quality in delivery.

Participating university students then deliver either two or three workshops on a chosen topic and present this at a pre-arranged local high school. The lesson plan requires the university students to explain engineering and scientific processes to high school students in the context of sustainable development and then the university students leading the high school students through an interactive activity developing/constructing a piece of appropriate technology to suit the topic being presented.

This project helps engage the university students in important dialogue with the community and the dissemination of knowledge on the social demands and ecological principles of the technology being presented whilst highlighting the important role of 
engineers in providing sustainable development solutions for the community (Goodman, 2002; Ambrose et al., 1998).

The HSO workshops were incorporated into the curriculum via the ESD unit to assist Curtin engineering students in their ability to communicate an engineering sustainability message and to importantly meet the broader requirements of Engineers Australia's Professional Engineering Attributes requiring students to develop skills in effective communication not only with engineers but also with the community at large (EA, 2010).

The university student feedback from this programme has highlighted many benefits from their participation including the development of team work skills, communication and increased understanding of ESD (Loden and Biswas, 2011).

Students were required to submit a 2 page report on their experience reflecting on the lessons that they learnt from the participation which completed their assessment requirement for the ESD unit.

The Future Engineers project can also potentially enhance the enrolment and engagement of female students, given their society and environmental focused engineering application motivations (deGrazia et al., 2001; Goodman, 2002).

EWBA plan to expand the programme to other universities and to continue to develop the resources supporting the Future Engineers programme and are seeking ongoing funding to support the programmes further development (Loden and Biswas, 2010).

\subsection{BEng under-graduate unit: 'engineering for sustainable development 201'}

ESD is a core engineering unit in the under graduate engineering degree at Curtin University. The unit focuses on industrial ecology principles and how they can be applied in the implementation of sustainable engineering solutions and decision making processes. The unit has been operating since 2006 and engages with students through inter and multi-disciplinary assignment tasks, industry guest lectures on applied sustainable engineering solutions and group work in tutorials. One of the major challenges faced in undergraduate engineering education is the lack of student maturity in understanding the context and value of sustainable engineering practice (Boyle, 2004; Biswas, 2012).

In addition, a gap exists between the knowledge that students enquire in their undergraduate degree and the applied understanding of sustainability which they will require in their future careers (King, 2007).

The course was developed given the gap that exists between the knowledge that students acquire at university and the concepts of sustainability and sustainable development that they need to practice as an engineer (Loden and Biswas, 2010).

Industrial ecology encompasses a broad range of sustainability related topics as it operates between the frontier of industrial production and the environment. Industrial ecology topics covered in the ESD course include life cycle assessment, cleaner production and eco-efficiency strategies, industrial symbiosis, green chemistry, green engineering and engineering design for the environment. Industrial ecology through its focus on sustainable production and consumption methodologies covers many topics included in sustainable development including inter and intra-generational resource challenges, the management of resources and production decision making from a cradle to grave perspective, and the mitigation of pollution as an externality of our engineering decisions. 
Mulder (2004) refers to the concept of the 'social engineer' as an important inclusion in engineering education given the implications of changing technology and its impact on society. Climate change, population growth and resource depletion are also increasing challenges for the modern engineer. These topics are also covered in ESD as a way of broadening the decision making horizon for the young engineer and to remove them from the silo of their discipline in providing relevant engineering solutions to these problems.

Bryce et al. (2004) elude to the increasing need for young engineers to be able to communicate more clearly, function more effectively in multi-disciplinary and multicultural environments and to more fully understand their ethical, social, professional, global and environmental responsibilities. To this end the ESD course involves students in assignment and tutorial activities that include students outside of their engineering discipline in activities that review many of the sustainability challenges faced in the modern world including life cycle thinking, carrying capacity constraints, ecological footprints, zero waste, and green engineering principles and design.

The main learning outcomes for the ESD unit are (Biswas, 2012):

- achieving a sound understanding of the basic theories of industrial ecology including cleaner production, industrial symbiosis and engineering design and how they can influence engineering decision making in achieving the triple bottom line goals of sustainable development

- development of skills in the assessment of sustainable engineering practice including energy and waste audits, life cycle assessment and eco-efficiency techniques

- a review of sustainable technologies including green chemistry, green engineering and bio-mimicry giving students an introduction to how science in nature can be followed to design a more efficient and environmentally sensitive process that conserves resources and reduces pollution

- strengthening multidisciplinary teamwork skill through group project participation and project delivery.

Assignments in the course have been designed to help the students apply theory to practice. The main assignment involves a life cycle assessment of chosen products/ processes and the utilisation of industrial ecology solutions like cleaner production, eco-efficiency strategies and industrial symbiosis to improve the sustainable development (triple bottom line) outcomes of the chosen products/processes. The students perform this assignment in multi-disciplinary teams and therefore becomes aware of the different engineering approaches needed in achieving more sustainable outcomes.

\subsection{Post-graduate degree: Master of Science in sustainability}

The MSc Sustainability degree is a post-graduate qualification for students interested in developing skills in sustainability management. The course is also founded on industrial ecology principles and techniques. Most of the enrolments in this degree are from students (including many engineers) in mining, refinery, manufacturing, agricultural production and engineering consultancy who are interested in developing skills to assist them in a broad range of business and industry sustainability challenges. The main sustainable development learning outcomes covered in the industrial ecology units in this qualification include: 


\section{Environmental systems 601}

- An understanding of the main causes of ecological imbalance impacting on ecosystems and biophysical cycles.

- Ability to identify, analyse and reflect on issues pertaining to environmental impacts including global issues related to population growth, water use, sustainable consumption, carrying capacity and environmental degradation.

- Understanding of the linkages between socio-economic drivers, ecosystem services and human wellbeing at local, national and global levels.

- Skills in applying the Millennium Ecosystem Assessment.

Global sustainable studies 601

- Understanding of and ability to apply, principles of sustainable production and consumption, within models of sustainable development (including dematerialising production consumption, and decoupling growth).

- Ability to outline and discuss concepts relating to global sustainable development, including: standard of living, human welfare, ecological footprint, weak and strong sustainability.

- An understanding of uncertainty in environmental decision making and the 'precautionary principle' and the 'Limits to Growth debate' and the relationship between growth and well being.

- Ability to predict, analyse and reflect on barriers to change, as well as propose technical solutions relevant to the sustainable development debate.

\section{Eco-efficiency strategies 601}

- An understanding of the application of the seven eco-efficiency strategies and their usage in process, product and service applications.

- Ability to distinguish between various eco-efficiency strategies and responses, including: ISO 14001 standard for Environment Management Systems; Kaizen management strategy and Design for the Environment (Eco Design).

- Recognise the value of eco-efficiency in reducing environmental impacts and the achievement of ISO 14001.

- An understanding of the applications of reuse, recovery and remanufacturing for green production and eco-design.

\section{Life cycle management 603}

- An understanding of the use and value of Life Cycle Assessment (LCA) and Life Cycle Management (LCM) in assessing the environmental performance of products and services.

- An understanding of the application of LCA in determining the carbon production 'hotspots' and the use of cleaner production strategies to improve environmental performance. 
- An understanding of the use of Environmental Management Systems in achieving compliance with the ISO 14001.

- Student assessment of specific industry application of LCA.

Sustainable energy 603

- An understanding of the current and potential role of sustainable energy compared with traditional fossil energies.

- Sustainable energy systems design and evaluation.

- Skills in sustainable energy scenario modelling and an ability to analyse current energy strategies from a triple bottom line perspective.

- Can prioritise and recommend strategies for increasing the role of sustainable energy inputs in production and consumption decision making.

Green engineering 603

- An understanding of the principles and concepts of green engineering, and its potential for economic, social and environmental benefits flowing to companies, consumers and the environment.

- An understanding of key green engineering technologies including, nanotechnology, nanoparticles, nanomaterials, bioengineering, bioprocessing, separation and purification processes, microreactors, microfluidics and micro-scale processing.

- Understanding of the 12 principles of green engineering and the principles of inherency.

\section{Industrial ecology 601}

- Understanding the role of cleaner production assessment, Life Cycle Assessment and environment management systems.

- Ability to design an industrial symbiosis programme that engages neighbouring industries in a collective approach to reduce waste, enhance energy and water efficiency and increase the physical exchange of waste/by-product materials.

- Skills in applying these three frameworks, analysing their results, and making recommendations for areas of operational and technical change within a company's production process and delivery.

Green chemistry 603

- An understanding of green chemistry, its development, history and contribution to sustainable development.

- An understanding of the underlying concepts in green chemistry including the role of catalysts and solvents, waste minimisation and feedstocks.

- An understanding of the principles of green chemistry including atom recovery, reduction of derivatives and design for degradation. 
Organisational strategies for sustainability 602

- An understanding of sustainability systems within organisations (e.g., energy, water, resources, waste, information and learning).

- The development of strategies to achieve sustainability within organisations including a focus on metrics, policies, procurement and creating the will for change.

- A review of organisational theory and organisational strategy evolution as it pertains to sustainability management and modelling strategies for self-sustainability.

\section{Accountability and reporting for sustainability 602}

- Identifying the values and metrics behind corporate social and environmental responsibility.

- An appreciation of current notable international frameworks for sustainability.

- Modelling self-accountability and goal setting and their value to sustainability issues.

- The role of accountability and reporting in facilitating change towards sustainability.

Corporate stewardship 602

- An understanding of the evolution of corporate stewardship, corporate citizenship and social and environmental responsibility and their potential application in achieving sustainability outcomes.

- An understanding of the impacts of 'legal personality' and articles of association in achieving corporate sustainability.

- An understanding of the ethical challenges separating corporate sustainable practices from 'greenwash'.

Public policy for sustainability 602

- An understanding of key international frameworks and institutions influencing the sustainability agenda.

- An understanding of the international convention processes including the Millennium Development goals, Kyoto protocol, climate change and carbon pricing that are influencing sustainability management in Australia and internationally.

- Recognition of the role of non-government organisations and civil society in the policy making process and a review of the policy instruments used to achieve behavioural change towards sustainability (economic, social and legal).

\section{Discussions}

Bordogna (2006) noted that

\footnotetext{
"Engineers stand at the fulcrum of scientific and technological change, creating new knowledge, artefacts and systems; stimulating economic development; creating wealth and jobs; sharpening the nations competitive edge; raising our prospects for more productive and satisfying lives; caring for the environment; and strengthening our national security."
} 
He concluded that "Engineering education is at the very heart of these issues. Demands are increasing for a holistic breed of engineers- graduates with the skill to work across intellectual, social and cultural boundaries".

Florman (1990) noted in his article 'The Civilised Engineer'

\begin{abstract}
"Many problems in our country, from ugly factories to environmental pollution, are blamed on engineers. Although such difficulties are actually the responsibility of the entire community, it is true that our country's engineers could play a more active role in creating technology that is more nobleaesthetically, environmentally and even morally- than what we have now."
\end{abstract}

Florman referred to the potential benefits of engineering students completing an undergraduate programme in the social sciences (liberal arts) enroute to a bachelor of engineering. He referred to this revised curriculum as an 'enriched educational programme' potentially able to produce a new generation of 'renaissance engineers'. Looking at the future of engineering education he surmised

\footnotetext{
"If we want to develop renaissance engineers, multi-talented men and women who will participate in the highest councils, we cannot educate them in vocational schools- even scientifically distinguished vocational schools- which is what many of our engineering colleges are becoming." (Florman, 2001)
}

The challenges for sustainable engineering education in Australia over the past 10 years have been considerable. The poor quality of political discourse on sustainable development apropos climate change and population growth, the lack of policy focus on economic development outside of the resources sectors (mining in particular), and the need for Universities to focus on student numbers and cost management rather than teaching and learning and research agendas for the future. In addition, engineering undergraduate education is in a flux as it considers the changes to the traditional four year Bachelor of Engineering degree in Australia being replaced by a five year Masters programme currently being adopted by some universities and the challenges associated with moving to a new untested model or staying with the status quo.

In de-constructing the challenges for sustainable engineering education, Curtin University's School of Engineering have taken a multi-level approach. In principle the programmes developed have been guided by the generic attributes provided by Engineers Australia (EA, 2010) including:

- $\quad$ ability to apply knowledge of basic science and engineering fundamentals

- ability to communicate effectively, not only with engineers but also with the community at large

- in-depth technical competence in at least one engineering discipline

- $\quad$ ability to undertake problem identification, formulation and solution

- $\quad$ ability to utilise a systems approach to design and operational performance

- $\quad$ ability to function effectively as an individual and in multi-disciplinary and multicultural teams, with the capacity to be a leader or manager as well as an effective team member

- understanding of the social, cultural, global and environmental responsibilities of the professional engineer, and the need for sustainable development 
- understanding of the principles of sustainable design and development

- understanding of professional and ethical responsibilities and commitment to them

- expectation of the need to undertake lifelong learning, and capacity to do so.

The Curtin School of Engineering has recognised the need to attract potential engineering students from local high schools and continually seeks to validate the modernity of the course and its salience as a strong engineering qualification. Increasing ESD education content and profile though the Future Engineers programme and the mandatory undergraduate programme is also a critical cornerstone in our ESD education strategy. The MSc Sustainability degree and its focus on industrial ecology solutions for sustainable development is also an important component in the Schools Lifelong Learning responsibilities.

In reflecting on current engineering roles in public policy Duderstadt (2008) notes the critical absence of engineers from either the leadership roles of business and government or major societal and community debates, and that this poses a threat to society in an increasingly technological world.

The question of how to produce the right engineers for our future is just beginning to be discussed in Australian engineering education. The Sustainable Engineering Group at Curtin University have been instrumental in the formation of a Sustainability Education Network amongst Australian Engineering Schools with the aim of developing essential leadership in the Engineering fraternity and to move the current focus on energy efficiency education to the broader challenge of engineering education for sustainable development.

Curtin's School of Engineering continue to work on other new initiatives to strategically develop the sustainability management competence and relevance of our undergraduate and post-graduate programmes. A new Master of Engineering with a sustainability major is currently being investigated, as is the introduction of a second mandatory unit 'Engineering ethics' as a capstone unit in the fourth and final year of the Bachelor of Engineering degree.

\section{Conclusion}

ESD involves many challenges but particularly its ability to reduce the environmental impact of our human production and consumption decisions and work with increasing resource depletion pressures. Approaches are being developed in engineering schools across Australia but in general these approaches are neither systematic, multi-disciplinary nor comprehensive in their ability to provide a broad holistic engineering education in the increasingly complex and integrated systems world of engineering decision making.

The engineer of the future will face an increasingly complex array of environmental and economic challenges, including: declining resource levels, rising water and energy prices, increasing demand for renewable energy, climate change induced risk management, human population growth pressures and aging populations. They will also need new science and technology and modes of engineering practice to solve these challenges.

Formative engineering education will need to deliver graduates who are well prepared for more complex systems with greater interdisciplinary understandings and capabilities. 
Engineering education will be characterised by lifecycle decision making based on sustainability principles, beyond what is currently on offer in the traditional engineering disciplines.

Industrial ecology principles and methodologies provide a very useful education pedagogy in meeting the challenges of engineering education for sustainable development. It is also an effective framework in both introducing the concepts of ESD and in providing a systems based approach in extending engineering sustainability knowledge and skills development.

\section{References}

Adetunji, I., Price, A., Fleming, P. and Kemp, P. (2003) 'Sustainability and the UK construction industry - a review', Proceedings of the Institution of Civil Engineers, Engineering Sustainability, Vol. 156, No. 4, pp.185-199.

Ambrose, S., Lazarus, B. and Nair, I. (1998) 'No universal constants: journeys of women in engineering and computer science', Journal of Engineering Education, Vol. 87, No. 4, pp.363-368.

Biswas, W. (2012) 'The importance of industrial ecology in engineering education for sustainable development', International Journal for Sustainability in Higher Education, Vol. 13, No. 2 , pp.119-132.

Bordogna, J. (2006) 'Round, flat or spiky: The world turns on an axis', Keynote Address, IEEE-USA Leadership Workshop 2006, 4 March, 2006, St. Louis, Missouri.

Boyle, C. (2004) 'Considerations on educating engineers in sustainability', International Journal for Sustainability in Higher Education, Vol. 5, No. 2, pp.147-155.

Bryce, P., Johnson, S. and Yasukawa, K. (2004) 'Implementing a program in sustainability engineering at the university of Technology Sydney', International Journal for Sustainability in Higher Education, Vol. 5, No. 3, pp.267-277.

deGrazia, J., Sullivan, J., Carlson, L. and Carlson, D. (2001) 'AK-12 University partnership: creating tomorrows engineers', Journal of Engineering Education, Vol. 90, No. 4, pp.557-563.

Duderstadt, J. (2008) Engineering for a Changing World: A Roadmap to the Future of Engineering Practice, Research and Education, The Millennium Project, The University of Michigan, USA.

Engineers Australia (EA) (2010) www.engineersaustralia.org.au/

Engineers Without Borders Australia (EWBA) (2011) www.ewb.org.au

Fenner, R., Ainger, C., Cruickshank, H. and Guthrie, P. (2005) 'Embedding sustainable development at Cambridge University Engineering Department', International Journal of Sustainability in Higher Education, Vol. 6, No. 3, pp.229-241.

Florman, S. (1990) The Civilised Engineer, Argus Press, Michigan Ill, 23 February.

Florman, S. (2001) 'Engineering and the concept of the elite', The Bridge, National Academy of Engineering, Winter, Washington.

Goodman, I. (2002) Final Report of Womens Experiences in College Engineering (WECE) Project, Goodman Research Group, Inc., Cambridge.

King, R. (2007) Engineers for the Future, Addressing the Supply and Quality of Australian Engineering Graduates for the 21st Century, Presentation to the Australian Council of Engineering Deans, Epping, NSW.

Loden, D. (2010) 'High School outreach modules', Engineers Without Borders [online], www.ewb.org.au/hsomodules (Accessed April 2013). 
Loden, D. and Biswas, W. (2010) 'Enhancement of university curriculum and secondary school education through utilisation of sustainable engineering and appropriate technology workshops', 2010 Australian Association for Engineering Education Conference, Sydney, pp.559-566.

Loden, D. and Biswas, W. (2011) 'Review of the enhancement of university curriculum through utilisation of sustainable engineering and appropriate technology workshops', 2011 Australian Association for Engineering Education Conference, Perth, pp.75-81.

McKinsey Global Institute (2011) Resource Revolution: Meeting the Worlds Energy. Materials, Food and Water Needs, Mckinsey Sustainability and Resource Productivity Practice, www.mckinsey.com/client_service/sustainability.aspx (Accessed April 2013).

Moskal, B. (2007) 'K-12 outreach: identifying the broader impacts of four outreach projects', Journal of Engineering Education, Vol. 96, No. 3, pp.173-189.

Mulder, K. (2004) 'Engineering education in sustainable development: sustainability as a tool to open up the windows of engineering institutions', Business Strategies and the Environment, Vol. 13, No. 4, pp.275-285.

Wordsworth, N. (2003) Staff Awareness is the Dominant Factor Affecting How Civil Engineering Consultancies Pursue Sustainable Development, Unpublished MPhil Dissertation, Department of Engineering, Cambridge University, Cambridge, UK. 